\title{
A favela onde moro: o território sob a perspectiva dos jovens
}

\author{
The favela where I live: the territory from the perspective of young \\ people
}

João Gabriel Trajano Dantas (https://orcid.org/0000-0002-8273-9137) ${ }^{1}$

Denise De Micheli (https://orcid.org/0000-0001-8546-4354)²

${ }^{1}$ Programa de PósGraduação em Educação e Saúde na Infância e Adolescência, Universidade Federal de São Paulo. Estrada do Caminho Velho 333, Jardim Nova Cidade. 07252-312 Guarulhos SP Brasil gabrieldantas.to@gmail.com

${ }^{2}$ Departamento de

Psicobiologia, Universidade

Federal de São Paulo.

Guarulhos SP Brasil

\begin{abstract}
This article examines a set of photographic productions created by six young people, living in a favela on the outskirts of São Paulo, seeking to reflect on their perception of the territory in which they live. A large part of the population of São Paulo resides in favelas, an urban phenomenon found on the outskirts of large metropolises. Despite the difficulty in accessing basic services, such as health, safety, culture and education, the favela is also a fertile space that nurtures feelings of belonging, solidarity and resistance in its residents. Young people, who also live and circulate in the streets and alleys of the favela, have a specific perspective on their own home territory. This is a qualitative and exploratory study, which uses photography as a research tool. The photographic and cartographic productions of the young people reflected different perspectives of the territory, revealing dimensions of leisure, community articulation, sociability, precariousness of the urban cleaning system, among others. Thus, the undertaking of creating visual narratives made it possible for different aspects of the favela to be exposed, discussed and analyzed.
\end{abstract}

Key words Adolescent, Photography, Social vulnerability, Sociocultural territory
Resumo $O$ presente artigo examina um conjunto de produções fotográficas criadas por seis jovens, moradores de uma favela da periferia de São Paulo, procurando refletir sobre a percepção que eles têm do território em que habitam. Grande parte da população de São Paulo reside em favelas, fenômeno urbano encontrado nas periferias de grandes metrópoles. Apesar da dificuldade do acesso a bens básicos, como saúde, segurança, cultura e educação, a favela também é espaço fértil que nutre sentimentos de pertencimento, solidariedade e resistência em seus moradores. As juventudes, que também vivem e circulam pelas ruas e vielas da favela, detêm um olhar especifico sobre seu próprio território de moradia. Esta é uma pesquisa qualitativa exploratória, que utiliza a fotografia como instrumento de pesquisa. As produções fotográficas e cartográficas dos jovens refletiram diferentes perspectivas do território, revelando dimensões de lazer, articulação comunitária, sociabilidade, precariedade do sistema de limpeza urbana, dentre outros. Sendo assim, o empreendimento da criação de narrativas visuais fez com que diferentes aspectos da favela pudessem ser expostos, discutidos e analisados.

Palavras-chave Adolescente, Fotografia, Vulnerabilidade social, Território sociocultural 


\section{Introdução}

A periferia compõe as margens dos centros urbanos das grandes cidades e, muitas vezes, comporta a precariedade do acesso aos bens básicos, como saúde, educação e segurança. A concentração das favelas, aglomerados habitacionais construídos sem planejamento urbano ou sanitário, nas periferias expressa claramente o aspecto social revelando acentuada condição de pobreza, marcadas pela escassez ou ausência de bens, observadas em vários núcleos dessas regiões ${ }^{1}$. $\mathrm{O}$ abismo social que separa ricos dos pobres é a força motriz de um desenvolvimento desigual da metrópole ${ }^{2}$.

Do ponto de vista histórico, Valadares ${ }^{3}$ ressalta que as favelas foram historicamente referenciadas como espaços insalubres, sem lei, anti-higiênicos, ilegais. Alvo de duras críticas por parte da saúde e segurança públicas, medicina e urbanismo, eram tratadas como problema social e moral pela sociedade, além de serem vistas como obstáculos ao desenvolvimento urbano. Estes foram alguns dos fatores que ocasionaram a remoção de sujeitos e famílias que moravam nessas regiões.

A busca pela expansão de uma cidade planejada, legal, em que as desigualdades e vulnerabilidades sociais não são equacionadas, mas escondidas dos olhos de parte da sociedade, resulta no crescimento de uma cidade considerada ilegal que é constantemente cerceada e combatida. Apesar de ser vista, muitas vezes, como a antítese de uma cidade ideal, a favela é um modo de organização urbana que antecede à formação das cidades, metrópoles ou centros urbanos, em outras palavras, configuram-se como uma forma antiga de organização habitacional de pessoas "numa sociedade ditada pela escassez" .

A precariedade do acesso aos bens básicos intensifica situações de vulnerabilidade que podem ser percebidas nessas regiões. Os elementos que compõem o conceito de vulnerabilidade são complexos, sendo diversos os fatores que influenciam os processos de desigualdade social, tais como: pobreza; baixa escolaridade; ausência de saneamento básico; baixa oferta de serviços públicos (da assistência social, educação, saúde, lazer e cultura) etc. A pobreza urbana é uma categoria econômica e política que, para além de ser mensurada e dimensionada, precisa ser compreendida como fenômeno que acompanha a urbanização e expansão da sociedade ${ }^{5}$.

As favelas reagem à assimetria da distribuição e concentração de bens, renda e trabalho dispersos pela cidade. São marcadas pela disputa do espaço urbano, do atrito provocado entre os terri- tórios habitáveis com aqueles onde a construção de moradia não é permitida.

Morar na favela torna-se uma solução para diversas famílias que não conseguem pagar por aluguéis nas regiões centrais ou em bairros com valor imobiliário acima de sua situação financei$\mathrm{ra}^{6}$. Pasternak e Ottaviano ${ }^{7}$, ao analisar os dados sobre as favelas brasileiras no Censo de 2010, afirmam que os principais motivos que alimentam o crescimento sistemático das favelas seriam a crise econômica, os preços dos aluguéis e a baixa oferta de moradias populares para as pessoas de baixa renda que, por sua vez, buscaram outra alternativa de ocupar o espaço urbano. Os autores corroboram com os comentários de Leeds e Cavalcanti, que reforçam a ideia de que a favela surge e se mantém como produto da crise urbana. Assim, A estrutura salarial é questão de diretriz e política pública nacional, somente limitadamente ligada ao nível de qualificação profissional da mão de obra em geral ${ }^{6}$ (p. 835).

As situações de pobreza e vulnerabilidades vivenciadas por grande parte da população mundial, em especial pelos moradores das favelas nas periferias de grandes centros urbanos, são desafios complexos que precisam ser analisados e superados conforme a realidade de cada território, de cada povo e de cada tempo, tendo em vista que o tamanho da cidade é diretamente proporcional à exposição de suas mazelas, ou seja, quanto maior e mais populosa, mais visíveis se tornam suas carências.

É a partir da precariedade urbana e descaso do poder público com as necessidades das comunidades que surgem as imagens que reforçam a favela como lugar da carência, do insalubre, espaço a ser preenchido pelos sentimentos humanitários, do perigo a ser erradicado pelas estratégias politicas que fizeram do favelado um bode expiató-

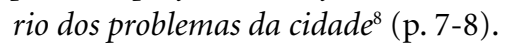

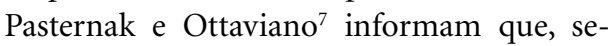
gundo o Censo de 2010, a população paulistana que reside em favelas é predominantemente mais jovem se comparada com o restante do município, onde $22 \%$ do total dos paulistanos têm até 30 anos, contra $28 \%$ dos moradores das favelas. Ou seja, as favelas são um importante lócus juvenil.

Lopes e Malfitano ${ }^{9}$ advertem sobre a urgência de pesquisas que explorem melhor as percepções da juventude. $\mathrm{O}$ olhar do jovem mostra-se sensível a diversas temáticas que atravessam seu próprio cotidiano e território, revela questões relacionadas à educação, lazer, cultura, desigualdade, vulnerabilidade social, saúde, dentre outros aspectos tão importantes para a contemporanei- 
dade. Sendo assim, aproximar dos olhares dos jovens para conhecer os diferentes aspectos que atravessam o cotidiano vivenciado numa favela pode produzir reflexões sobre esses territórios a partir do olhar de quem nele vive.

A juventude é um fenômeno multidimensional que deve ser considerada a partir de sua significação em diferentes contextos da vida social.

Estamos diante um fenômeno inteiramente aberto, em interação construtiva e destrutiva constante com o universo sócio-cultural em que está inserido, em permanente relação de amor e ódio, continuidade e ruptura e muitos outros paradoxos próprios dessa fase da existência que, para nós, adultos, segue e seguirá sempre como uma realidade ao mesmo tempo estranha e familiar ${ }^{10}$.

Dentro deste cenário, a fotografia surgiu como importante recurso documental deste estudo, permitindo a feitura de cartografias visuais que possam revelar aspectos da percepção de jovens moradores de uma favela da Zona Leste de São Paulo.

A categoria autofotográfica, como modalidade de pesquisa, permite a expressão das percepções do sujeito, exterioriza visões de mundo que são impressas nas imagens registradas, podendo revelar situações sociais complexas e elementos que compõem o cotidiano, fatores estes que justificam sua utilização como recurso metodológico privilegiado ${ }^{11}$. O conjunto de fotografias registradas por um sujeito cria uma espécie de cartografia visual.

O termo cartografia vai além do mapeamento geográfico, amplia a possibilidade de expressão que acompanha a existência e os sentidos produzidos por determinada situação de vida e desejos. Segundo Guatarri e Rolnik ${ }^{12}$, as cartografias acontecem na circulação por territórios de vida e afeto, são criadas no atrito entre o mundo interno com os espaços externos aos sujeitos.

A fotografia constitui-se como campo profissional e artístico bastante complexo, em que são encontrados diferentes conceitos, variáveis, associações, técnicas etc. A triangulação estabelecida entre o fotógrafo, o aparelho fotográfico e o ambiente atravessa uma rede de significações que vão desde contemplação do ambiente em busca de uma cena, de um texto evocado pelo olhar atento do fotógrafo que, ao manipular o aparelho a fim de capturar o melhor ângulo, aperta o gatilho da câmera que resulta no registro da cena numa superfície plana, a fotografia ${ }^{13}$.

Este trabalho emerge com a intenção de investigar a relação que os seis jovens, moradores de uma favela da Zona Leste da cidade de São
Paulo, estabeleceram com o território onde moram. Dessa forma, procurou-se ampliar a voz dos olhares dos participantes que teriam a missão de fotografar o território onde residem, circulam e pertencem.

Para isso, é inevitável apresentar questões sobre: como apreender o olhar dos jovens? E se dermos câmeras fotográficas aos jovens de um bairro da periferia, bairro este marcado por diferentes processos de desigualdade social, o que seus olhares captariam? Quais aspectos apontariam em seu próprio território? Como articulariam melhorias e investimentos territoriais? Foi com base nesses questionamentos que este estudo se desenvolveu e investiu esforços para apreender o foco de jovens habitantes de uma favela da Periferia de São Paulo.

\section{Percurso metodológico}

Trata-se de um estudo qualitativo exploratório que utilizou a autofotografia como recurso metodológico, onde seis jovens, com idades entre 15 e 17 anos, registraram sua visão sobre as diferentes relações que constituem o espaço onde habitam. Os instrumentos analisados pela pesquisa foram as fotografias dos jovens e as entrevistas.

Com múltiplas formas de registrar aspectos do cotidiano, a fotografia explora a relação de luz e sombra de ambientes diversos, imprimindo no papel uma visão de mundo percebida pelo fotógrafo. Assim, todo e qualquer gesto do dia-a-dia, por mais comum e repetitivo, ganharia nova aura, através da fotografia. Não era só ver a realidade, mas percebê-la, alcançá-la, tocá-la ${ }^{14}$ (p. 26).

$\mathrm{Na}$ busca por estas apreensões, o pesquisador acessou os informantes da pesquisa e seus respectivos responsáveis com a colaboração da liderança comunitária, uma Agente Comunitária de Saúde moradora da região. Na ocasião, foram realizados os convites mediante apresentação da pesquisa e elucidação de dúvidas recorrentes. As leituras dos Termos de Consentimento Livre e Esclarecido (TCLE) e de Assentimento foram realizadas junto aos jovens e seus responsáveis, cujo os aspectos éticos envolvidos na pesquisa foram devidamente detalhados. Os responsáveis e jovens ficaram com as cópias dos documentos assinados. A pesquisa foi aprovada pelo Comitê de Ética em Pesquisa (CEP) da Universidade Federal de São Paulo (Unifesp).

Num momento posterior, foi realizada a entrega das câmeras descartáveis, que tinham a capacidade de registrar 28 fotografias, acompa- 
nhada de uma explicação prática sobre seu funcionamento. Os participantes tiveram a liberdade para realizar quantos registros desejassem, dentro desse limite. Não restando dúvidas sobre seu manuseio, estabeleceu-se um período de quinze dias para que pudessem explorar o território e registrar suas imagens.

Ao término deste período, o pesquisador dirigiu-se à residência dos participantes para retirada da câmera, conversar sobre amenidades, possíveis intercorrências e combinar uma data para a realização da entrevista, com as fotografias reveladas.

Com as imagens em mãos, o pesquisador reuniu-se individualmente com cada um dos participantes, em suas respectivas residências, para realização de uma entrevista semiestruturada que abordou os contextos e as motivações para o registro de cada foto. As entrevistas foram gravadas, transcritas e analisadas, por meio da análise de conteúdo, conforme proposto por Bardin ${ }^{15}$. Desta forma, buscou-se identificar as categorias que emergiram a partir das fotografias e entrevistas.

Em alguns casos, a realização das entrevistas tornou-se um desafio, pois ocorreram dentro do espaço de moradia dos participantes, onde a passagem, presença e intervenção de alguns familiares foram inevitáveis. Quando possível, foi priorizado realizá-la em lugares mais protegidos, a fim de diminuir as interferências externas.

Para assegurar o anonimato dos participantes, optou-se por atribuir-lhes pseudônimos com nomes de algumas ruas da região. Desta forma, este estudo conta com o olhar de Fernão Mendes Pinto, Abaíra, Vuearana, Caiçara do Rio do Vento, Ajuana e Arauá.

\section{Resultados e discussões}

Os atos fotográficos dos jovens resultaram num acervo de 85 fotografias que foram registradas próximas das residências dos participantes que, por sua vez, revelaram espaços de circulação e pertencimento, públicos e privados. Já as entrevistas geraram cerca de 3 horas e 50 minutos de gravação.

Não houve consenso sobre como a câmera acompanhou os percursos de cada participante, porém, alguns elementos se repetiram nas cartografias realizadas como, por exemplo: a organização das praças, ruas e vielas; o incômodo com o lixo; a paisagem que mistura céu com o conjunto de casas na encosta do morro etc. Ou seja, por mais personalizado que fosse o olhar de cada jovem, sempre existiram elementos que foram compartilhados e recorrentes entre eles, respeitando a perspectiva de cada um, como se juntos pudessem realizar uma fotografia panorâmica da favela onde habitam.

Embora se tenha observado elementos similares retratados nas imagens dos seis jovens, a triangulação fotógrafo-câmera-ambiente foi bastante singular. Abaíra registrou imagens dentro de sua própria casa e de seu trabalho; Fernão Mendes Pinto fotografou paisagens que podem ser vistas a partir de seu quintal e da igreja que frequenta; Vuearana registrou imagens que, segundo ela, remetiam a sua infância e outras relacionadas às delicadezas que encontrava pelas ruas e calçadas por onde andava; Caiçara do Rio do Vento pegou sua bicicleta e fotografou ruas, praças e serviços públicos de suporte social; Ajuana levou sua câmera para escola e retratou imagens com seus amigos, assim como fotografou vielas e a escadaria de uma praça; e Arauá, que também fotografou seu ambiente residencial, mostrou diferentes perspectivas dos caminhos que realiza em seu dia a dia, movendo-se para seus destinos diários. Desta forma, cada participante representou seu território pessoal a partir da ótica do seu próprio cotidiano.

Os resultados apresentados no Quadro 1 dão indícios de que as câmeras fotográficas descartáveis mapearam o mundo externo dos participantes, motivados por seu mundo interno (desejos, medos, gostos e desgostos). Conforme pode ser observado, as entrevistas com menor duração foram as de Abaíra e Fernão Mendes Pinto, que também apresentaram as menores quantidades de registros fotográficos.

No Quadro 2, os jovens apontaram as fragilidades e potencialidades que percebem na favela em que residem. Observa-se que muitas das imagens retratadas pelos participantes denunciam a fragilidade das ações do Estado, tanto no que diz respeito à insuficiência de equipamentos públicos para suporte às famílias em situação de vulnerabilidade social, quanto à precariedade de um serviço de coleta de lixo e saneamento básico que responda as demandas da população, inclusive para a manutenção de praças, áreas de lazer, esportes e outros espaços coletivos. Por outro lado, também foram observadas imagens que denotam as potencialidades da região, deixando transparecer dimensões das ações comunitárias nos espaços de sociabilidade e lazer, como por exemplo, em áreas verdes com árvores frutíferas, praças para encontros com amigos e familiares, o baile funk e espaços para prática de esportes, como o campo de futebol. 
Quadro 1. Registros fotográficos, duração das entrevistas e lugares fotografados pelos participantes $(\mathrm{n}=6)$.

\begin{tabular}{|l|c|c|l|}
\hline Pseudônimo do jovem & $\begin{array}{c}\text { Quant. de } \\
\text { fotografias }\end{array}$ & $\begin{array}{c}\text { Tempo de } \\
\text { entrevista }\end{array}$ & \multicolumn{1}{|c|}{ Locais fotografados } \\
\hline Fernão Mendes Pinto & 8 & $13 \mathrm{~min} .25 \mathrm{seg}$. & Próprio quintal; e igreja. \\
\hline Abaíra & 4 & $8 \mathrm{~min} .46 \mathrm{seg}$. & Própria casa; local de trabalho; e viela. \\
\hline Vuearana & 17 & $42 \mathrm{~min} .28 \mathrm{seg}$. & $\begin{array}{l}\text { Academia que frequenta; ruas; calçadas; praças; } \\
\text { campo de futebol; e escola. }\end{array}$ \\
\hline Ajuana & 19 & $49 \mathrm{~min} .20 \mathrm{seg}$. & $\begin{array}{l}\text { Escola; ruas; vielas; “escadão; praças; caminho pra } \\
\text { UBS; igreja; e própria casa. }\end{array}$ \\
\hline Arauá & 18 & $58 \mathrm{~min} .39 \mathrm{seg}$. & $\begin{array}{l}\text { UBS; própria casa; ruas próximas; travessa do bairro; } \\
\text { e praça. }\end{array}$ \\
\hline Caiçara do Rio do Vento & 19 & $38 \mathrm{~min} .17 \mathrm{seg}$. & $\begin{array}{l}\text { Nascente; ruas; praça; calçadas; pizzaria do bairro; } \\
\text { Centro de Acolhida; Centro de Referência de Assis- } \\
\text { tência Social; e ciclofaixa. }\end{array}$ \\
\hline
\end{tabular}

Fonte: Elaborado pelos autores.

Quadro 2. Potencialidades e fragilidades do território retratadas pelos jovens.

\begin{tabular}{|c|c|c|}
\hline Jovem & Potencialidades & Fragilidades \\
\hline Arauá & $\begin{array}{l}\text { Espaços verdes; atividades na UBS; praças } \\
\text { limpas; solidariedade das pessoas pobres; e } \\
\text { grafites. }\end{array}$ & $\begin{array}{l}\text { Lixo urbano; ratos no ambiente doméstico; praças } \\
\text { depredadas; preconceito; racismo; e machismo. }\end{array}$ \\
\hline Vuearana & $\begin{array}{l}\text { Árvores; praças para jogar xadrez; jardins; } \\
\text { campo de futebol; e possibilidade de criar } \\
\text { memória com o lugar onde mora. }\end{array}$ & $\begin{array}{l}\text { Uso do cigarro; bitucas de cigarro nas ruas; lixos e } \\
\text { entulhos jogados pela calçada; e falta de cuidado } \\
\text { com o lugar onde mora. }\end{array}$ \\
\hline Abaíra & $\begin{array}{l}\text { Paisagem vista do quarto (céu e favela); e } \\
\text { baile funk. }\end{array}$ & Não relatou nenhum elemento. \\
\hline Ajuana & $\begin{array}{l}\text { Praças revitalizadas pela comunidade; a pai- } \\
\text { sagem vista do segundo andar da casa (o céu } \\
\text { e o morro); igreja; trabalhos criativos na } \\
\text { escola; escadão pintado com trechos de poe- } \\
\text { mas; árvores frutíferas das praças; e organi- } \\
\text { zação e desenvolvimento da favela. }\end{array}$ & $\begin{array}{l}\text { Emaranhado de fios no escadão; escola; lixos nas } \\
\text { vielas; panfletos pós-eleições jogados no chão; e } \\
\text { estrutura da favela. }\end{array}$ \\
\hline $\begin{array}{l}\text { Caiçara } \\
\text { do Rio do } \\
\text { Vento }\end{array}$ & $\begin{array}{l}\text { Ciclofaixas; pizzaria; áreas verdes; parques e } \\
\text { praças para atividades de lazer e prática de } \\
\text { esportes; e limpeza das praças. }\end{array}$ & $\begin{array}{l}\text { Insuficiência de serviços públicos de suporte social } \\
\text { (Centros de Referência de Assistência Social (Cras) } \\
\text { e Centros de Acolhida); falta de sinalização nas } \\
\text { ruas; famílias pobres; terrenos baldios; insuficiência } \\
\text { de creches; falta de calçadas; falta segurança para o } \\
\text { ciclista; poluição de nascentes e riachos; e ineficácia } \\
\text { de um serviço de coleta de lixo para região. }\end{array}$ \\
\hline $\begin{array}{l}\text { Fernão } \\
\text { Mendes } \\
\text { Pinto }\end{array}$ & $\begin{array}{l}\text { Igreja; campo de futebol; paisagem vista do } \\
\text { quintal; e trabalho. }\end{array}$ & Pessoas falando palavrão; brigas; e música alta. \\
\hline
\end{tabular}

Fonte: Elaborado pelos autores.

\section{Favela, a cidade do centro}

Todos os jovens da pesquisa, com exceção de Vuearana, nomearam o espaço onde habitam de "Favela". Termo também utilizado para designar o campo de pesquisa deste trabalho, representada pela fotografia de Abaíra (Figura 1).

Apesar de serem colocadas numa mesma categoria, cada favela apresenta suas particularidades que reagem à estrutura física, social e am- 


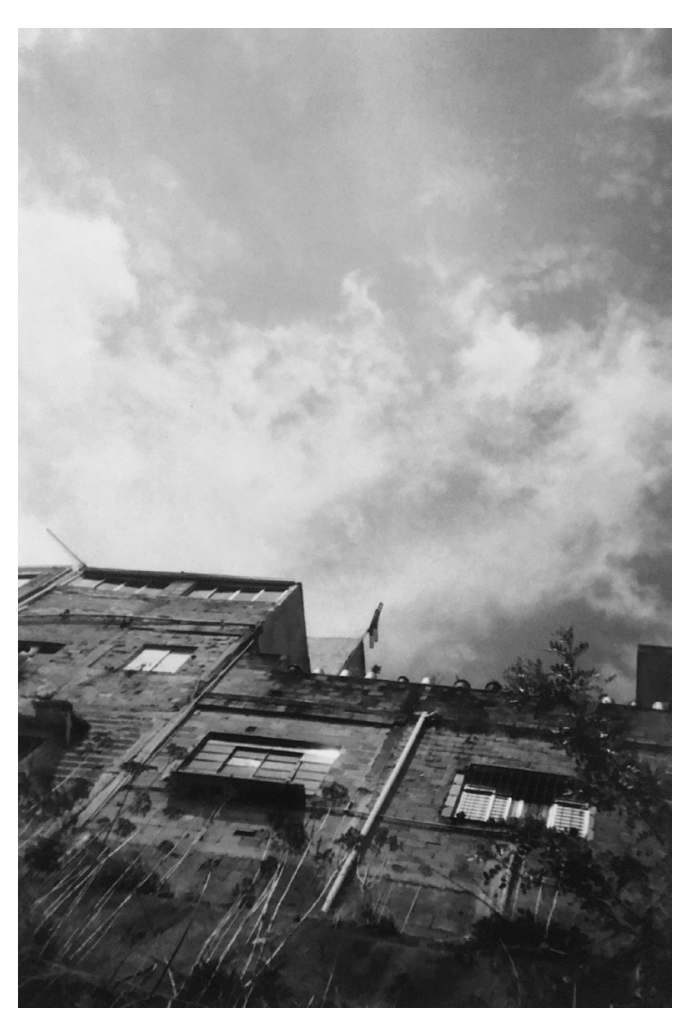

Figura 1. Imagem 1.

Fonte: Fotografia tirada por Abaíra.

biental do lugar. Ou seja, qualquer generalização destes espaços restringe as possibilidades de olhar aspectos únicos que surgem em cada território.

Isto foi percebido por Ajuana. A jovem relatou sobre a heterogeneidade das favelas que conhece, onde cada uma apresenta características próprias, que respondem à arquitetura do lugar e ao modo de vida das pessoas que ali moram. Ao falar sobre a sua, comenta que se orgulha da organização local, representada no modo em que a comunidade se organiza para interagir e modificar espaços compartilhados, seja amenizando a sujeira causada pela concentração de lixo, seja pela revitalização da praça e do campo de futebol, aspectos que serão desenvolvidos a seguir.

$E$ Eue assim, comparando com outras...Não outros bairros, mas com outras favelas que eu fui, é...Acho que é mais a questão da organização mesmo. (...)quando era pequena esse morro que tem aqui ele era tudo de barro, é...e agora tem mato tipo, evoluiu muito, eu cresci e vi essa evolução, é muito bom ver isso. E tem outros lugares que parecem o mesmo, sabe? Que continua a mesma coisa, eu acho que a gente lá, na Sapolândia, ela cresceu bastante, eu gosto muito disso, tem o estacionamento, onde tem vários carros, eu acho isso muito bacana, eu gosto muito. Acho que eu multiplicaria essa parte da organização, do avanço. [sic] (Ajuana).

Ajuana, que sempre residiu na região, pôde observar as modificações que ocorreram em seu bairro. Acompanhou as melhorias nos diferentes espaços adjacentes a sua casa e daqueles que frequentava, por este motivo, destacou que a favela está em constante transformação. Apesar de notar a qualidade da organização local e evidenciá-la como aspecto positivo, suas narrativas (visual e oral) não deixam de perceber que tanto a precariedade da arquitetura das casas quanto a fragilidade do sistema de limpeza urbana são obstáculos importantes que dificultam o desenvolvimento social, elementos que, segundo sua opinião, precisam de melhor atenção do governo.

A favela está mais relacionada com a ideia de fronteira do que de exclusão, os sujeitos, habitantes desse espaço fronteiriço, encontram-se a um só tempo excluídos de um território socialmente dominante, às vezes de modo perverso, mas em espaços-entre e em suas formas inovadoras de sobrevivência e sociabilidade ${ }^{16}$ (p. 299).

Leeds e Cavalcanti ${ }^{6}$, ao criticarem o modo em que algumas pesquisas são conduzidas nesses espaços, alertam sobre o equívoco comum de situar a favela como problema social, afirmam que tal sentença é enganosa e arbitrária. Embora os jovens tenham utilizado o termo Favela para designar o espaço em que moram, nenhum deles utilizou o termo 'favelado' para nomear seus moradores, o que nos faz pensar sobre como esse termo pode ser empregado de maneira pejorativa. Para este autor, a utilização do termo 'favelado’ está geralmente associado aos discursos de uma sociedade elitista e por alguns cientistas sociais, afirma que são categorias ideológicas e muito enganadoras, porque indicam um estado de ser e não uma condição mais ou menos temporária de vida, resultante de causas exteriores ${ }^{6}$ (p. 835).

\section{Território comunitário: cuidado coletivo com os espaços de sociabilidade e lazer}

As praças, espaços verdes, de esportes e lazer surgiram nas narrativas visuais e orais da maioria dos participantes, na qual quatro jovens destacaram a relevância desses espaços no cenário urbano da favela, dando uma visão panorâmica sobre sua importância para a comunidade na produção de encontros, diálogos, atividades físicas, lazer, convívio etc. 
As praças e áreas verdes urbanas surgem como espaços de circulação, lugares a serem praticados, podem ser ocupados de diferentes formas: piqueniques, atividades físicas e de lazer, como aponta Caiçara do Rio do Vento (Figura 2) que, por sua vez, avalia que a presença de árvores nas praças é capaz de embelezar o ambiente, contrastando com o restante da cidade de São Paulo, sempre cercada por grandes arranha-céus.

Arauá, amante do verde, reforça ao nos dizer que a presença de árvores torna esses espaços mais acolhedores e continentes, possibilitando refúgio aos problemas pessoais e sociais que enfrenta em seu dia a dia.

[falando sobre as praças] Onde eu posso ficar sozinha, tipo... é, ficar sozinha mesmo. Não precisar ficar olhando um monte de coisas, ficar vendo as coisas que acontecem em casa, aí eu saio e fico lá, mas tenho que voltar. [sic](Arauá).

É nesse contexto que a praça ganha diferentes sentidos na vida desses jovens e influenciam diretamente o olhar afetivo que têm sobre seu próprio território. Para Arauá e Caiçara, as praças ganham outros contornos, surgem em suas narrativas como espaços de encontros, reflexões pessoais e refúgio.

A praça também pode ser um espaço de intervenções que operam mudanças sociais im- portantes. Essa perspectiva é convergente com os resultados da pesquisa desenvolvida pelas autoras Silva, Oliveira e Malfitano ${ }^{17}$, que analisaram o papel deste equipamento como mediador do empreendimento de práticas territoriais possibilitando delinear tecnologias sociais que favoreçam a democratização e a problematização de formas de enfrentamento à situação de vulnerabilidade social a que estão submetidos os sujeitos em situação de vulnerabilidade social ${ }^{17}$.

A manutenção das áreas verdes urbanas se justifica pelo seu potencial de influenciar positivamente a qualidade de vida da população, trazendo diversos benefícios para seus frequentadores. Bargo ${ }^{18}$ destaca a importância dos espaços verdes saudáveis para o controle da poluição do ar trazendo um impacto positivo na proteção ambiental da cidade, além dos efeitos diretos sobre a saúde mental e física da população. Existe também a produção de sociabilidades que são intermediadas pelos diferentes espaços comunitários.

Vuearana evidencia, em sua cartografia visual, a presença de um campo de futebol que foi construído e reformado, resultado da articulação comunitária local. Também é neste espaço que Fernão Mendes Pinto e seus colegas frequentam para jogar algumas partidas, assim como diversos outros moradores da região.

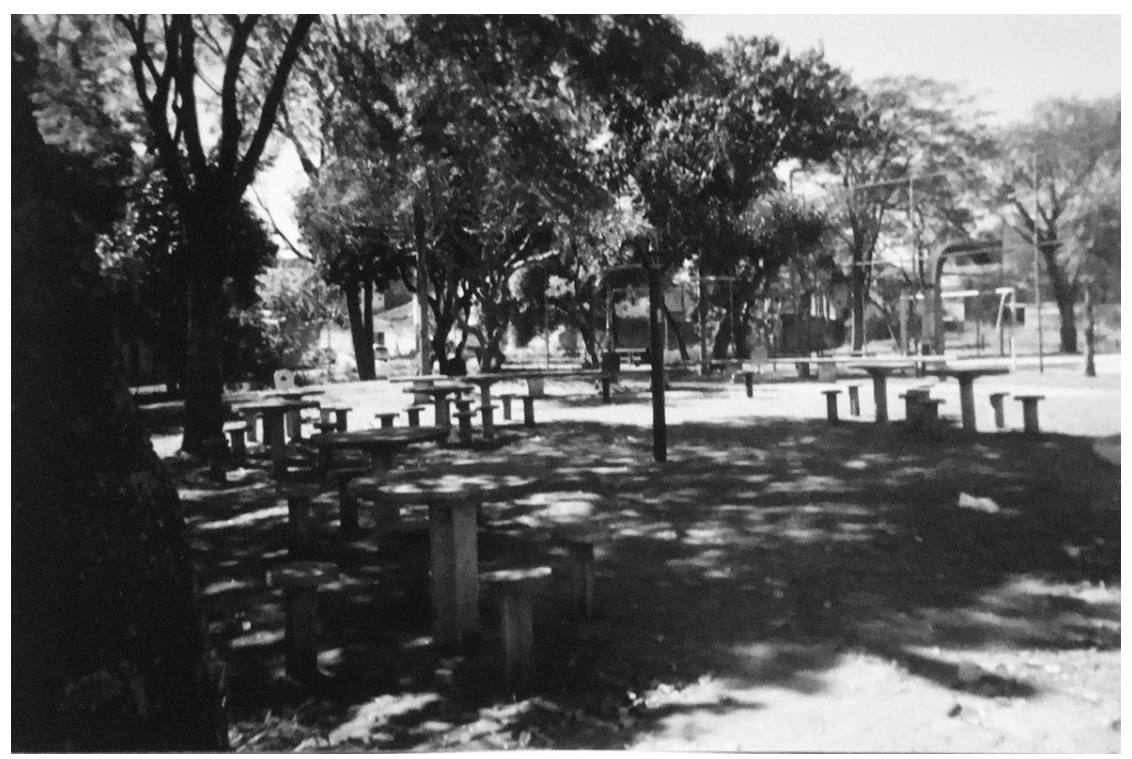

Figura 2. Imagem 2. 
Aqui tem um campo que eles reformaram, fizeram um monte de coisas legais, e do ladinho ainda tem umas... umas mesas sabe? Que tem um joguinho de xadrez pras pessoas jogar, é bem aconchegante ali [sic].(Vuearana).

Ajuana realizou uma série de seis fotografias (algumas delas expostas nas Figuras 3 e 4) de uma escadaria que dá acesso a um ambiente onde a jovem se encontra com alguns amigos para comer amoras, acerolas e conversar sobre a vida, revelando mais um espaço em que relações de convívio e lazer acontecem. $\mathrm{O}$ aspecto central destas fotografias está nas cores, nas palavras escritas em cada degrau e principalmente no fato de ter sido resultado da organização comunitária para revitalização daquele espaço.

Mais uma vez, Ajuana e Vuearana pontuam a importância da participação social na manutenção e personalização de espaços públicos muitas vezes esquecidos tornando-os em ambientes agradáveis, acolhedores, cheio de cor e poesias, capaz de promover e criar bons encontros. Quan-

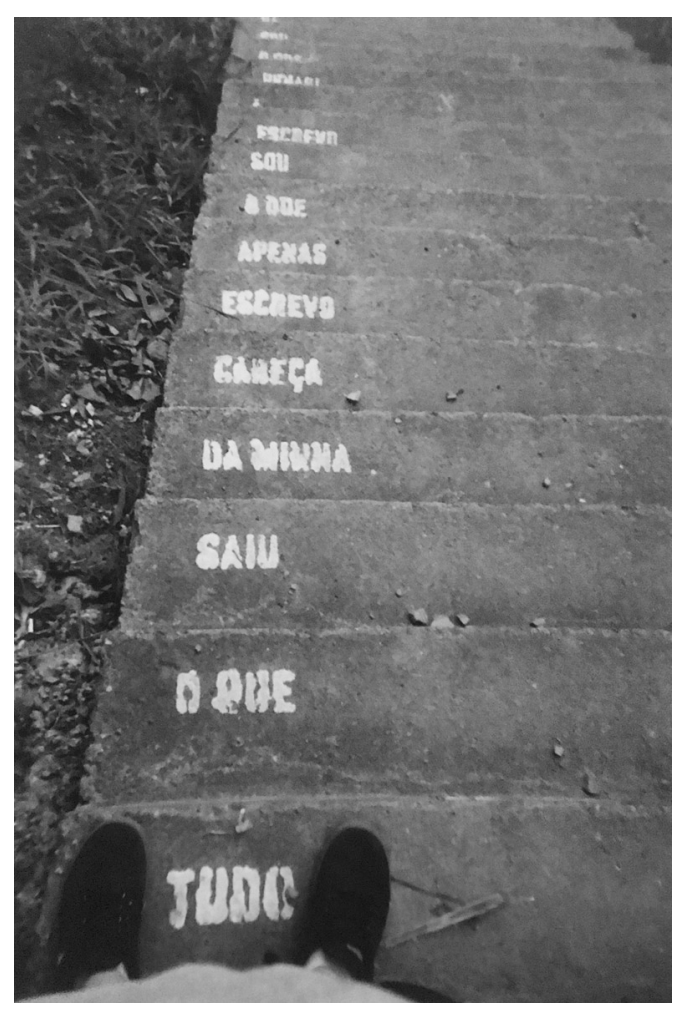

Figura 3. Imagem 3.

Fonte: Fotografia tirada por Ajuana. do a poesia pinta o concreto cinza de uma escadaria, deixa-a mais chamativa aos olhos de quem passa, mais do que degraus que levam alguém de um lugar a outro, a escada se transforma e pode ser admirada, lida e contemplada. Chama a atenção dos jovens a ponto de agenciar encontros entre amigos, proporcionando momentos de lazer e sociabilidades.

A gente começa com essa parte aqui, daí está escrito: "você já foi poesia hoje?". Aí a gente vai descendo a escada e no canto esquerdo e direito tem frases assim, né? A gente vai descendo e lendo né, daí quando a gente desce tudo isso e você olhar pra trás tem essa... Muito da hora. Nossa quem fez isso foi muito criativo [sic]. (Ajuana).

Essas fotos e comentários revelam como a dimensão estética desses espaços importam para os jovens, operam como traços expressivos de suas identidades, sinônimo de beleza. Essas fotos são também recortes da presença artística em territórios muitas vezes carentes de equipamentos culturais e de programações artísticas continuadas.

Entretanto, a ação da comunidade na revitalização da praça e do campo de futebol denuncia a fragilidade do Estado no território, tanto na criação de espaços de lazer e esporte, quanto para a manutenção dos que já existem. A população local, ao investir esforços para a revitalização desses espaços, reivindica sua importância social, articula saberes e fazeres criativos para seu cuidado, tornando-os mais atrativos, convidativos e acolhedores.

Para alguns jovens da pesquisa, a praça dialoga diretamente com seu universo juvenil, despertando curiosidade e vontade de permanecer. Essa linguagem estimula a prática de encontros nos espaços comunitários e sociais, ao contrário do que é percebido em praças esquecidas, mal iluminadas ou em péssimas condições, que se transformam em pontos viciados de depósito de lixo, lugar de venda, uso e abuso de drogas, dificultando outras possibilidades de trocas entre seus frequentadores. Pelo contrário, contribuem para o aumento da exposição a determinadas situações de riscos aos jovens que ali frequentam.

Cabe reiterar que revitalização, transformação e reforma de espaços públicos e comunitários compõe uma série de estratégias que reforçam as relações de sociabilidade, lazer e do direito à cidade das juventudes.

Ajuana e Arauá evidenciaram uma temática importante para grande parcela da juventude da periferia, que é o reconhecimento da pixação, do pixo, como manifestação juvenil, produção estética e identitária, muitas vezes realizada como 


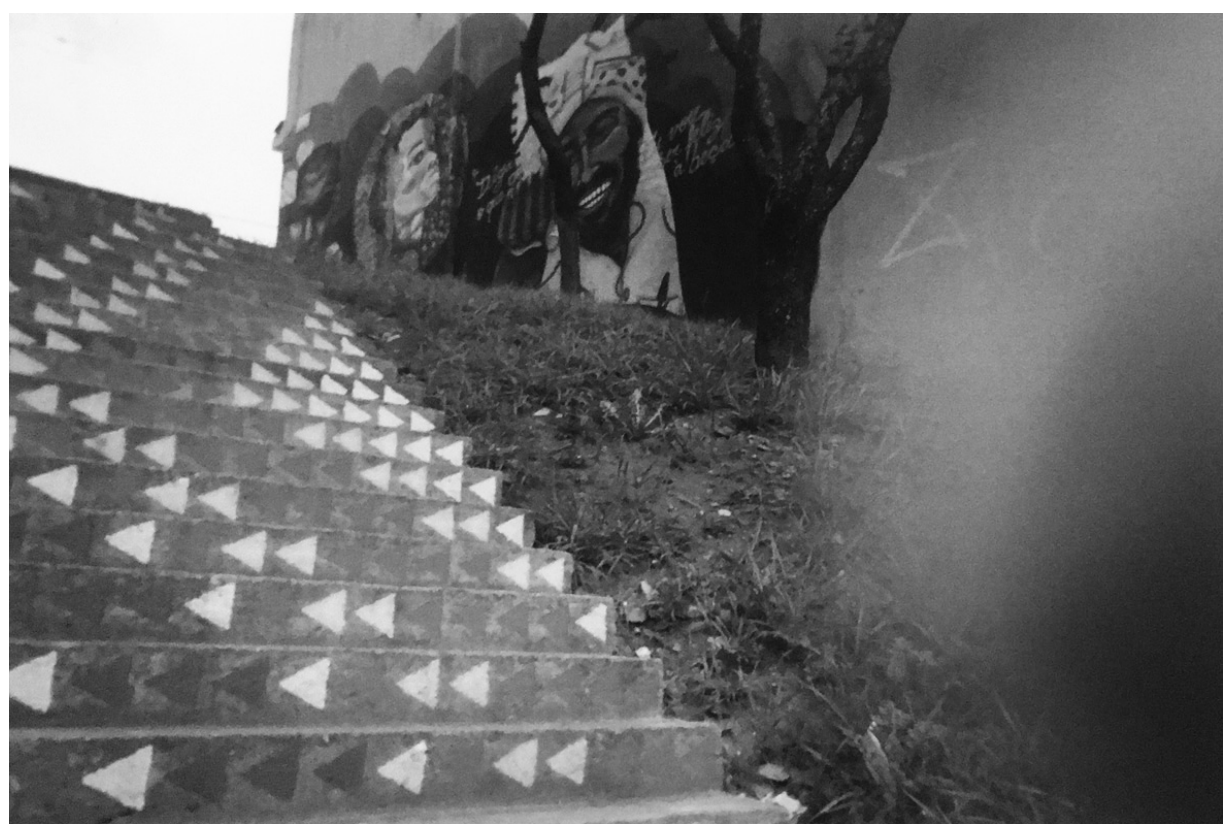

Figura 4. Imagem 4.

Fonte: Fotografia tirada por Ajuana.

forma de protesto, em oposição ao governo, mas que também se mostram como resultado de mobilização social para modificação estética do espaço.

Os autores deste artigo adotam a grafia com " $\mathrm{x}$ " e não com "ch", contrapondo-se às regras gramaticais, respeitando o modo como os pixadores utilizam o termo em sua prática.

Coisa bem de nós da favela, em quase todas as paredes de lá tem uma pixação e é sempre... nunca é uma frase ou nada disso, é sempre o nome da pessoa, aqui acho que está escrito "Caique", sempre uma assinatura, "Caio" aqui embaixo, sempre assinatura das pessoas [sic]. (Ajuana).

Quando a gente fala de pixação é...Eu pelo menos penso em muito: "Ah! Revolução, ah! Anarquismo" coisas relacionadas a isso né, ou então frases de efeito contra o governo. [sic]. (Arauá).

Este aspecto observado pelas jovens corrobora com o estudo etnográfico realizado por Perei$\mathrm{ra}^{19}$, cuja pesquisa revela as relações que os jovens constroem a partir da pixação (Figura 5). O autor afirma que os estudos sobre esta atividade têm a capacidade de revelar diferentes dinâmicas construídas pelos jovens da periferia com os centros urbanos $^{19}$.

A pixação é uma manifestação juvenil de cunho transgressor relacionada intimamente à cultura hip hop. Os pixadores da cidade de São Paulo são, em sua grande maioria, jovens moradores da periferia que se descolam para o centro da cidade e, mediados pela atividade da pixação, criam redes de sociabilidade ${ }^{19,20}$. Como as jovens retrataram em suas fotografias, as pixações também estão presentes nos muros das vielas da favela em que moram, redimensionando a estética do local.

Outra manifestação ligada ao hip-hop que aparece na pesquisa é o funk. Durante a entrevista com Abaíra, sua tia entra na conversa para falar do baile funk próximo de sua casa, apontando-o como um espaço de sociabilidade e construção de identidade da jovem.

As coisas que você faz estão por aqui mesmo, só o trabalho que fica um pouco mais distante? (Entrevistador).

Isso mesmo. (Abaíra).

E o funk aqui no bairro. (Tia).

Você gosta do funk aqui do bairro? (Entrevistador).

Gosto (risos). (Abaíra).

Acontece sempre? (Entrevistador).

Todo final de semana. É aqui pertinho, sabe o ponto de ônibus aqui? É pertinho. (Abaíra).

$\mathrm{O}$ baile funk é um fenômeno urbano típico das favelas e periferias, ocorrem preferivelmen- 


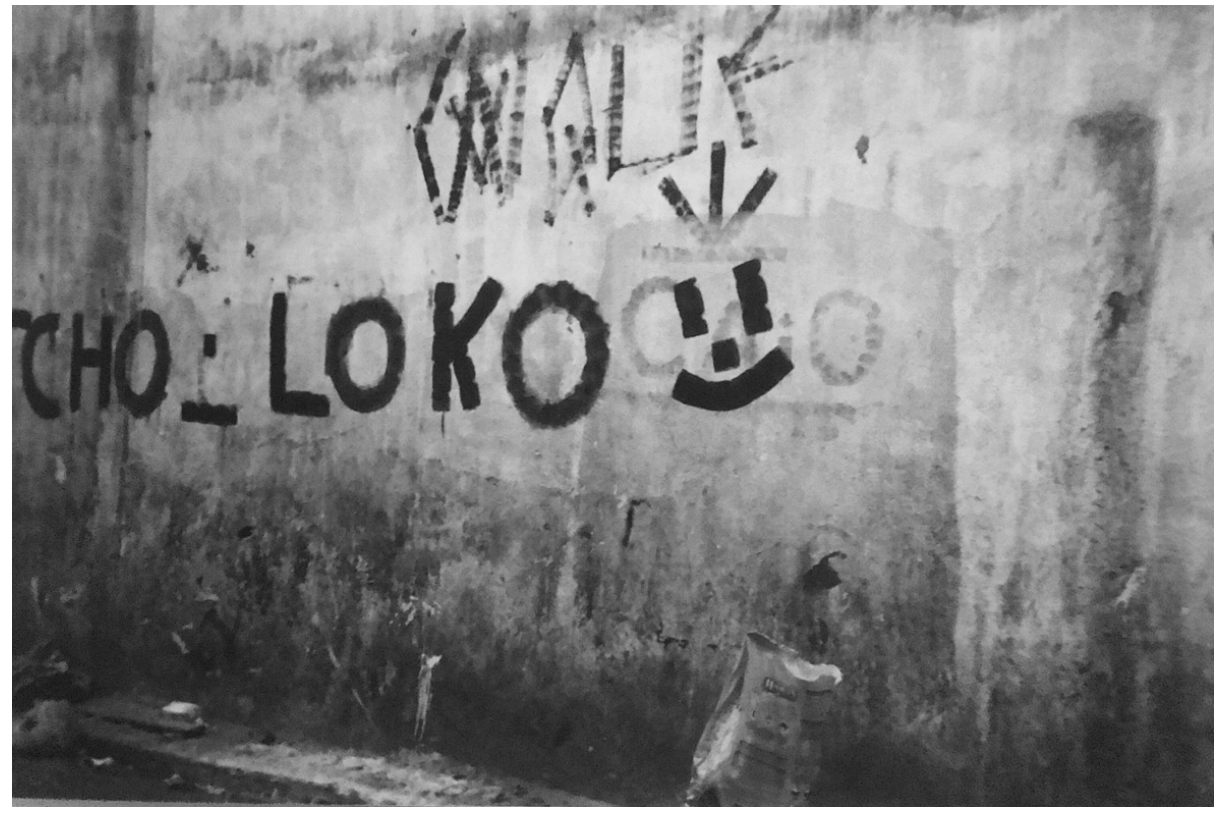

Figura 5. Imagem 5.

Fonte: Fotografia tirada por Ajuana.

te em ruas ou praças de fácil acesso ${ }^{21}$. É a forma que seus moradores utilizam para fazer uso do próprio território como espaço de lazer, sociabilidade e entretenimento. O uso principal da cidade, isto é, das ruas e das praças, dos edifícios e dos monumentos, é a Festa (que consome improdutivamente, sem nenhuma outra vantagem além do prazer e do prestígio, enormes riquezas em objetose em dinheiro $)^{22}$ (p. 12).

Dayrell ${ }^{23}$ investigou os significados que jovens da periferia endereçavam à experiência com grupos musicais ligados aos estilos do rap e funk. $\mathrm{O}$ autor procurou desconstruir a imagem imposta aos jovens da periferia e moradores da favela, que são constantemente associados à violência $\mathrm{e}$ marginalidade, o que evidencia a desqualificação social de tudo o que essa juventude produz. Dayrell ${ }^{23}$ destaca que a existência de uma produção cultural efervescente protagonizada pelos jovens produz grupos que facilitam experiências de coletividade e sociabilidade, estruturantes para produção de subjetividade na vida dos sujeitos e dos espaços.

Coelho $^{21}$ analisou algumas fotografias realizadas no interior de práticas culturais vivenciadas por jovens moradores dos subúrbios e favelas do Rio de Janeiro e nos conta que o arranjo de práticas encontradas na periferia (pixação, bailes funk, torcidas organizadas e jogos de futebol) envolvem um alto fluxo de jovens e auxiliam na produção de espaços de sociabilidade.

O estreitamento das relações com o território vai além da busca por melhores oportunidades de trabalho, o que sustenta são as vivências e experiências produzidas no e com o território que repercutem diretamente na qualidade de vida da comunidade. As relações com o território são estreitadas e aprofundadas quando a busca por espaços de identidade é colocada em jogo, tal como acontece na reforma comunitária de uma praça, campo de futebol, nos coletivos de pixadores e nos bailes funk, aspectos que compõem o cotidiano dos jovens, cenários identitários que facilitam a ampliação das suas redes de sociabilidade, auxiliando na demarcação de sua identidade frente ao território em que habitam.

O mundo da cultura aparece como um espaço privilegiado de práticas, representações, símbolos e rituais no qual os jovens buscam demarcar uma identidade juvenil. Longe dos olhares dos pais, professores ou patrões, assumem um papel de protagonistas, atuando de alguma forma sobre o seu meio, construindo um determinado olhar sobre si mesmos e sobre o mundo que os cerca. ${ }^{23}$ (p. 119). 


\section{Limpeza urbana}

As questões sobre a limpeza urbana, poluição de nascentes e rios e a importância de um sistema de coleta de lixo doméstico eficaz foi amplamente discutida e fotografada por alguns participantes: Arauá fotografa alguns sacos de lixo junto da parede; Caiçara do Rio do Vento escolhe evidenciar a poluição de um riacho que corre ao lado da praça em que frequenta; Vuearana registra o acúmulo de entulhos ao lado do campo de futebol; e Ajuana fotografa o lixo que fica depositado entre as vielas, na escadaria por onde passa.

Durante as entrevistas com as participantes, ao discutirem este aspecto, pontuam que esse comportamento social é resultado da fragilidade de um serviço de limpeza urbana, que dificulta o acesso para a coleta em alguns pontos do bairro, fazendo com que a população crie o hábito de concentrar o lixo doméstico em lugares específicos. Arauá reconhece que a presença de ratos em sua moradia também se dá pelo acúmulo de lixo nas redondezas. Em sua fotografia, deseja representar "todo o lixo que vê por aî" [sic] (Figura 6).

Caiçara do Rio do Vento, em suas narrativas, afirma que é de responsabilidade do Estado organizar uma rede de coleta de lixo eficaz que se ajuste às necessidades da população, o que não anula os deveres e responsabilidades da comuni- dade em relação ao lixo que produzem e lugares em que descartam, tais aspectos também foram evidenciados em suas fotografias.

A presença do lixo não é resultado da pobreza das famílias que ali vivem, e sim, um produto de uma série de fatores relacionados ao comportamento social da população associados à fragilidade de uma rede de coleta de lixo eficiente.

Em contraposição a praças e espaços verdes, as fotografias de Caiçara do Rio do Vento (Figura 7) alertam para a fragilidade da estrutura da rede de esgoto local, muitas vezes despejados nas nascentes e riachos locais, revela a necessidade de uma política de saneamento básico para a região. A jovem pede por maior atenção do governo em relação a limpeza e despoluição das nascentes e riachos que atravessam sua região.

Temas como proteção ambiental têm sido amplamente discutidos ao redor de todo o mundo, um assunto importante e necessário para o desenvolvimento sustentável e harmônico da cidade. As favelas, muitas vezes, apresentam aspectos precários de saneamento básico, porém, tal fator transforma-se numa justificativa social que, acrescida de outras, "legitimava" a remoção das favelas.

Ao discutir sobre as relações construídas com os espaços, estamos nos referindo sobre como os jovens são afetados por eles, como se identificam,

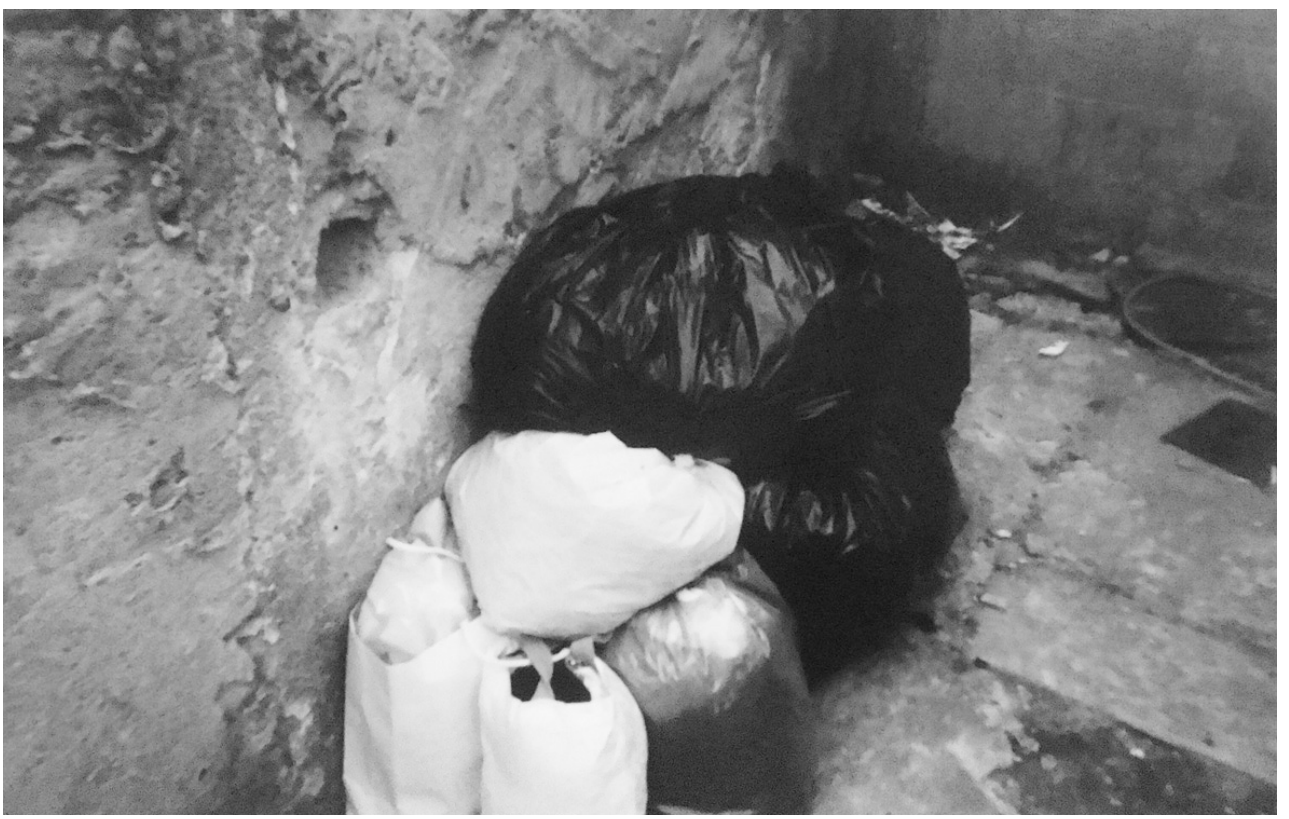

Figura 6. Imagem 6. 


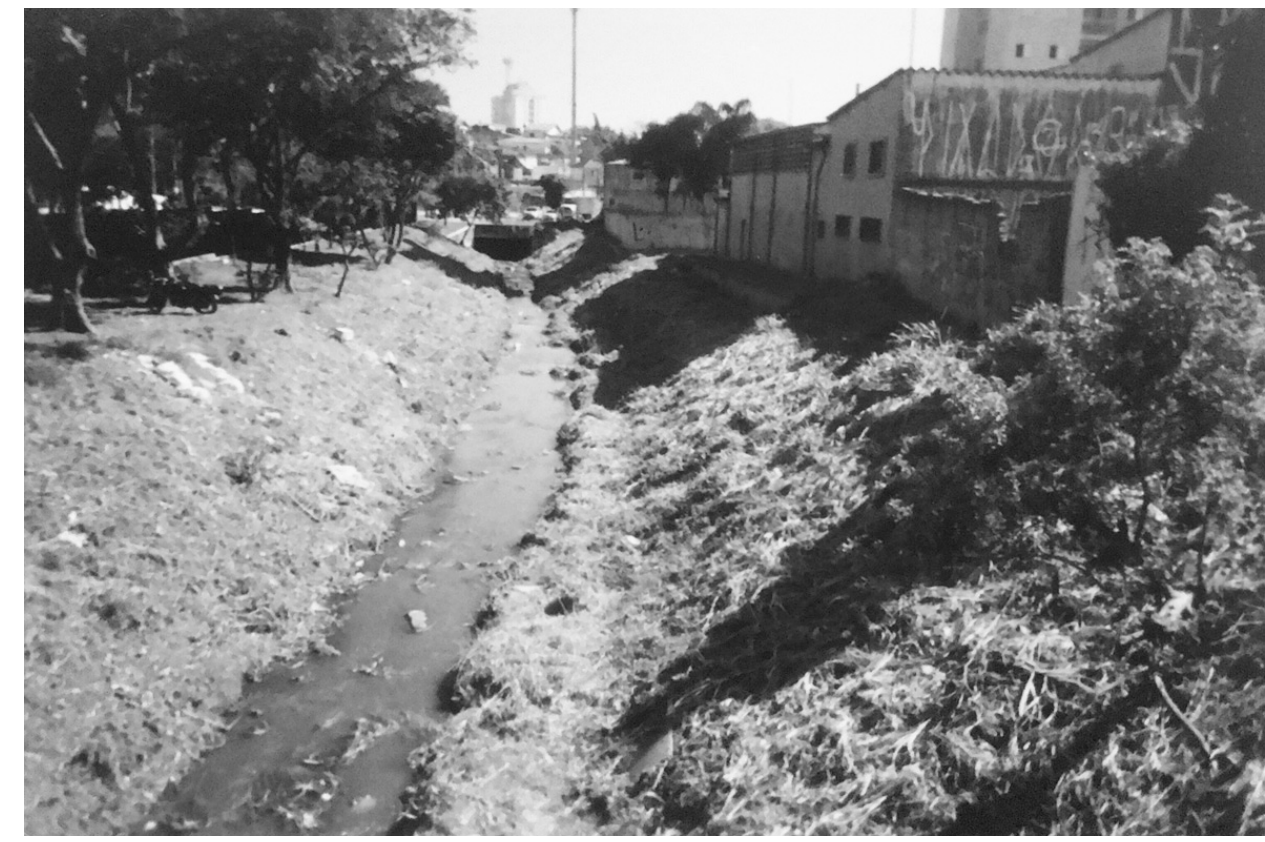

Figura 7. Imagem 7.

Fonte: Fotografia tirada por Caiçara do Rio do Vento.

ou não, com os elementos presentes em seu território e sobre como podem ser agentes de mudança, atuando coletivamente no desenvolvimento de ações que beneficiem o bairro onde moram. É assim que uma praça, o campo de futebol, pixações ou o baile funk não se limitam apenas no que se pode ver. Existe uma produção criativa dos e nos espaços que, por sua vez, são preenchidos por atividades físicas, de lazer, culturais, de convívio, dentre outra não mapeadas.

\section{Considerações finais}

O exercício de descrição e análise empreendido neste artigo ressalta, a partir do ponto de vista juvenil, diferentes vetores que estão em movimento entre os espaços e as interações sociais presentes na favela, onde seus moradores lhe atribuem usos, práticas e sentidos.

As cartografias visuais dos participantes revelaram a favela como um espaço fértil, onde as ações comunitárias são estruturantes na vida dos sujeitos e do território. Encontramos sua expressão nos diferentes sentidos que foram produzidos com a criação, e constante aprimoramento das práticas e espaços de lazer, esporte, sociabilidade, cultura e entretenimento. As transformações sentidas pelos jovens dão indícios que transcendem a leitura da favela enquanto espaço-dormitório, mas ao contrário, nos revela um território com uma complexa trama social, espaço pulsante que é compartilhado, vivido e praticado por quem nele reside.

Do ponto de vista da abordagem metodológica colocada em prática nesta pesquisa, as câmeras fotográficas se mostraram como instrumentos que produziram outras possibilidades de analisar o olhar juvenil sobre o próprio território. Um elemento versátil e instigante que motivou a maioria dos jovens, revelando seu importante impacto enquanto recurso metodológico em pesquisa qualitativa tomando a fotografia como expressão artística.

As cartografias visuais e as entrevistas reforçam o quanto os jovens podem ser atores ativos na elaboração, implementação e avaliação de políticas públicas para juventude voltadas para o desenvolvimento social da periferia, reforçando a importância do diálogo com os sujeitos, o cotidiano e a realidade dos diferentes territórios. Para isso, existe a urgência em reconhecer a po- 
tência de vida que circula entre as ruas e vielas das favelas, sem desconsiderar ou subestimar os efeitos deletérios provocados pela desigualdade, vulnerabilidade social, pobreza e violência que também existem, mas é na potência que as possibilidades de transformação se encontram.

\section{Colaboradores}

Todos os autores tiveram contribuição substancial neste trabalho, no que se refere à concepção do projeto de pesquisa, análise, redação e revisão crítica, certificando que participaram suficientemente do trabalho para tornar pública sua responsabilidade pelo conteúdo. 


\section{Referências}

1. Andrade CCA. Letramento visual: trabalhando a fotografia documental no ambiente escolar [dissertação]. Itabaiana: Universidade Federal de Sergipe; 2015.

2. Carril L. Quilombo, favela e periferia: a longa busca da cidadania. São Paulo: Anablume/Fapesp; 2006.

3. Valladares LP. A invenção da favela: do mito de origem a favela.com. Rio de Janeiro: FGV; 2005.

4. Kehl L. Breve histórico das favelas. São Paulo: Claridade; 2010.

5. Santos M. Metamorfoses do espaço habitado. $6^{\mathrm{a}}$ ed. São Paulo: Editora da Universidade de São Paulo; 2014.

6. Leeds A, Cavalcanti M. Quanto vale uma favela. Antropol 2018; 8(3):831-848.

7. Pasternak S, Ottaviano C. Favelas no Brasil e em São Paulo: avanços nas análises a partir da leitura territorial do Censo de 2010. Cad Metrop 2016; 18(35):7599.

8. Zaluar A, Alvito M. Um século de favela. $5^{\mathrm{a}}$ ed. Rio de Janeiro: Fundação Getúlio Vargas; 2006.

9. Lopes RE, Malfitano APS. Ação social e intersetorialidade: relato de uma experiência na interface entre saúde, educação e cultura. Interface (Botucatu) 2006; 10(20):505-515.

10. Costa ACG. Protagonismo juvenil, adolescência, educação e participação democrática. $1^{\mathrm{a}}$ ed. Salvador: Fundação Odebretch; 2000.

11. Silva LN, Koller SH. O uso da fotografia na pesquisa em Psicologia. Estud Psicol 2002; 7(2):237-250.

12. Guatarri F, Rolnik S. Micropolíticas: cartografias do desejo. Petrópolis: Vozes;1996.

13. Flusser V. Filosofia da caixa preta: ensaios para uma futura filosofia da fotografia. São Paulo: Annablume; 2011.

14. Câmara M. Urubu rei: uma imagem fotojornalística e suas multimodalidades. In: Almeida DBL, organizadora. Perspectivas em análise visual: do fotojornalismo ao blog. João Pessoa: Editora UFPB; 2008.

15. Bardin L. L'Analyse de contenu. Paris: Presses Universitaires de France; 1977.

16. Tavares SMG, Albertini P. Moradia e corporeidade em espaços liminares: um estudo sobre formas de subjetividade na favela. Paideia 2005; 15(31):299-308.
17. Silva MJ, Oliveira ML, Malfitano APS. O uso do espaço público da praça: considerações sobre a atuação do terapeuta ocupacional social. Cad Bras Ter Ocup 2019; 27(2): 438-447.

18. Bargo DC. Mapeamento e análise das áreas verdes urbanas como indicador de qualidade ambiental urbana: estudo de caso de Paulínia-SP [dissertação]. Campinas: Universidade Estadual de Campinas; 2010.

19. Pereira AB. As marcas da cidade: a dinâmica da pixação. Lua Nova 2010; 79:143-162.

20. Ceará AT, Dalgalarrondo P. Jovens pichadores: perfil psicossocial, identidade e motivação. Psicol USP 2008; 19(3):277-293

21. Coelho G. Monstros, rojões, bambus, bolas e o fundão: encantarias em performances de uma juventude rueira. Rev Bras Estud Presença 2018; 8(2):197-218.

22. Lefebvre H. O direito à cidade. $5^{\mathrm{a}}$ ed. São Paulo: Centauro; 2008.

23. Dayrell J. O rap e o funk na socialização da juventude. Educ Pesq 2002; 28(1):117-136.

24. Souza ML. Proteção ambiental pra quem? A instrumentalização da ecologia contra o direito à moradia. Mercator 2015; 14(4):25-44.

Artigo apresentado em 28/05/2020

Aprovado em 01/04/2021

Versão final apresentada em 03/04/2021

Editores-chefes: Romeu Gomes, Antônio Augusto Moura da Silva 